\title{
A DIALÉTICA DAS EMOÇÕES
}

Rosivaldo Pellegrini

Professor da Universidade Estadual de Londrina

E-mail:valdo@sercomtel.com.br

\section{Resumo}

Este artigo busca analisar alguns aspectos sobre as emoções e suas múltiplas determinações no sentido da possibilidade de sua integração, contradição e superação frente às dimensões de ordem política, econômica, cultural e social.

Palavras-chave: fetiche da mercadoria; coisificação do humano; espetáculo do cotidiano; sujeito-coletivo.

bjetivamos construir uma reflexão voltada para o valor das emoções em faces das atividades do cotidiano, do avanço tecnológico e da mediação da mercadoria. Nesse sentido, buscamos trabalhar alguns apontamentos da relação dialética das emoções e a evolução social. Mas, quais seriam os critérios para processar tal relação?

A compreensão seria o primeiro passo. O segundo estaria na iniciativa da modificação dessas emoções para nossa "evolução". O terceiro colocaria a necessidade da "integração" da nossa emoção em nível pessoal com a de outro ou outros, canalizando e socializando emoções.

No senso comum surgiria uma questão imediata antes de adentrarmos nessas três etapas almejadas. Que emoções seriam canalizadas e socializadas? Poderemos, exemplificando, selecionar o amor, a amizade e a confraternização em detrimento do ódio, da inveja 
e da ganância? Não cairíamos numa visão maniqueista dos sentimentos, simplificando uma questão complexa, posto que o contraponto para a identificação da existência do amor poderia residir no ódio? Sentimentos opostos, mas que exigiriam uma compreensão de seu surgimento, contradições e superações. Isso nos remete, portanto, a pensarmos na origem das emoções e no processo de sua construção e transformação, nas influências que recebemos, no valor social das experiências pelas quais passamos com suas diferenças históricas e culturais.

Surgem mais perguntas que respostas. E à medida em que respondemos, novas questões se apresentam. Somos seres humanos, sociais, abertos constantemente aos questionamentos, superações e a novos questionamentos. Porém, do ponto de vista tecnológico tudo indicaria uma "evolução" extraordinária. De imediato poderíamos pensar nos computadores, na robótica ou no genoma, que não deixam dúvidas quanto a essa "evolução". A questão que imediatamente se colocaria é a do aproveitamento social dessa "evolução" e da compreensão e transformação das emoções no sentido "qualitativo" que busca acompanhar esse processo. Nesse sentido, parece existir descompasso e contradições entre o desenvolvimento tecnológico e o desenvolvimento das emoções.

Devemos reconhecer os avanços da Psicologia e da Psiquiatria em inúmeros aspectos na compreensão e na integração da pessoa ao convívio social. Os estudos das mudanças de comportamento devido às influências externas (social) e internas (pessoal) colocam novos desafios à medida que essa Psicologia e essa Psiquiatria evoluem. Porém, convenhamos, trata-se da evolução recente em termos históricos. Freud, Jung, Reich, Foucault, Piaget, Skinner entre outros são pensadores clássicos, mas contemporâneos. Isso colocaria uma indagação de senso comum, imediata. Seria preciso dar tempo ao tempo para a "evolução qualitativa", especificamente para a "evolução" da pessoa, da "harmonia" de suas emoções e, portanto, de sua conduta passa consigo mesma e para com os demais? Mas, esse questionamento não nos conduziria a uma visão linear e individualista da história? Linear, em razão de desconsiderar as contradições existentes. Individualista, porque poderíamos subestimar o peso da esfera social, colocando a possibilidade de superação exclusivamente no indivíduo. 
Se estudarmos outras épocas, outros momentos, outras culturas, podemos constatar sociedades e comunidades com aceitável convívio social. Nenhuma idealização paradisíaca, porém razoável nível de relacionamento social e pessoal. Pensaríamos primeiramente nas sociedades primitivas. Tecnologia extremamente rudimentar, conhecimento cientifico incipiente, culto aos deuses e à natureza, etc. Exemplificamos não no sentido de resgatar "o bom selvagem" de Rousseau, mas de desmistificar a noção de que o tempo caminha em termos de passado, presente e futuro, linearmente falando. Istoé, a idéia que predomina é a de que não podemos voltar ao passado, com isso não apreendendo nada desse passado e ficando perdidos no presente imediato, sem futuro. Nossas emoções do passado, nossas lembranças, boas ou más, nosso patrimônio histórico, tudo ficaria esquecido. Passaria a importar a velocidade, a competição, o poder, a mercadoria, etc. O passado parece estar presente apenas enquanto saudosismo, quando muito nos bons aspectos.

Predominaria portanto, hoje, a velocidade, o imediato das coisas, com relações superficiais e descartáveis, caracterizando o critério a ser dado às emoções, o que pode conduzir ao individualismo possessivo, apresentando características oriundas da acumulação de capital, multifacetada, confundindo-se no âmbito da economia, da política e da cultura.

Podemos ver que Fredric Jameson contribui com apontamentos brilhantes sobre esse aspecto:

Nos últimos anos tenho argumentado com insistência que tal (a atual) conjuntura é marcada por uma desdiferenciação de campos, de modo que a economia acabou por coincidir com a cultura, fazendo com que tudo, inclusive a produção de mercadorias e a alta especulação financeira, se tornasse cultural, enquanto que a cultura tornou-se profundamente econômica, igualmente orientada para a produção de mercadorias. Portanto, não devemos nos surpreender com o fato de que conjecturas sobre nosso assunto em questão podem na verdade ser tomadas como afirmações sobre o capitalismo tardio ou sobre as políticas de globalização. (JAMESON, 2001, p.14).

Tudo indica que o discurso neoliberal reduz a política à economia, a economia reduz-se às finanças, esta ao mercado, e o mercado passa a ser visto como jogo. Pensamos na dimensão internacional desse discurso 
e no intervencionismo militar do governo Bush. Na influência que exerce na população americana e nos demais países, principalmente nos mais pobres e de culturas diferentes do protestantismo. Processar-se-ia um verdadeiro exacerbamento de emoções negativas; ódio fomentando ódio, num círculo vicioso de interesses territoriais, políticos e econômicos. Portanto as emoções colocadas historicamente parecem caminhar a reboque dessa política gananciosa que visa o poder da mercadoria: seja o petróleo, seja o território, ou seja mesmo a satisfação interna para certas camadas da população americana acostumadas a intervir. Que fique claro: não se trata de defender países ditatoriais ou determinada religião, mas de respeitar culturas e o direito de soberania interna dos povos.

Nesse sentido, questionamos em que medida o Brasil estaria na condição de ser "a bola da vez?" Com nossas diferenças culturais, nosso extenso território, riquezas historicamente dilapidada pela burguesia interna e externa, mas ainda possuindo enorme potencial na natureza, no território, nas matas, nas pessoas. Temos a fama de ser um povo extremamente emotivo, com religiões diversas, mistura de culturas, de raças. Darcy Ribeiro via nesses aspectos a força de um povo, a beleza das diferenças culturais e ao mesmo tempo a contradição presente diante da extrema desigualdade social. Nesse contexto, a construção de um povo emotivo, com história de lutas, perdas, conquistas.

Partindo-se do pressuposto de que já nascemos inseridos num determinado contexto social, com sua cultura, suas formas específicas de organização, seus movimentos sociais, partidos, associações, empresas, estado, etc., pensar-se-ia nas relações que construímos e em suas transformações. $\mathrm{O}$ fato de já estarmos inseridos nesse meio não colocaria a possibilidade de conhecermos melhor nossas emoções, vivenciando a experiência do dia-a-dia? Em cada organização seja na família, no trabalho, na Universidade ou na Igreja, nossas emoções parecem confundir-se ou solidificar-se com essas experiências. Parecemos agir no imediato das situações. Porém, a imediaticidade do cotidiano das nossas vidas, a velocidade que a mercadoria dinheiro cobra implacavelmente, parecem não deixar muitas opções para refletirmos sobre os sentimentos que se constroem no nosso interior e nas relações com os demais. O imperativo de "ganhar a vida", e mesmo quando se supõe esta "estar ganha", parece colocar cada vez mais a 
necessidade de corrermos mais, reforçando o lema de que "tempo é dinheiro". Portanto, estarmos inseridos no problema poderia ajudarnos a vivenciá-lo, conhecê-lo, não necessariamente superá-lo, ao convivermos com ele. Entendemos que as emoções acompanham esse ritmo. Se concordarmos que a vida cotidiana acompanha as necessidades da luta pela mercadoria e pelo poder, as emoções desse cotidiano parecem seguir essas mesmas necessidades. Um acompanhamento extremamente contraditório medida que somos impelidos cada vez mais para termos mercadorias, parece que nossos desejos de posse se fortalecem. Nossas emoções confundem-se, mas o desejo exposto, por exemplo pelas mercadorias num Shopping, condicionaria a hierarquizar nossas emoções. Colocaria a necessidade, muitas vezes supérflua, como necessidade imperiosa para adquirir, pela posse, o prazer da compra dessa mercadoria. Quando isso não se realiza, muitas vezes por absoluta falta de recursos materiais, a emoção da posse para o prazer parece ser substituída pela frustração ou pela revolta. Por outro lado, a mercadoria ali permanece, alheia a essas emoções, incólume, aguardando ser possuída pelo valor pelo qual está exposta. Então, passamos a adorá-la de todas as formas para satisfazer nossas necessidades, reais ou imaginárias. Nossas emoções parecem ficar fetichizadas na adoração do objeto.

Há que se levar em consideração a construção de nossas emoções na atividade cotidiana e sua influência no processo de conscientização. Heller coloca apontamentos que nos auxiliam nessa reflexão:

A vida cotidiana é a vida do homem inteiro; ou seja, o homem participa na vida cotidiana com todos os aspectos de sua individualidade, de sua personalidade. Nela, colocam-se "em funcionamento" todos os seus sentidos, todas as suas capacidades intelectuais, suas habilidades manipulativas, seus sentimentos, paixões, idéias, ideologias. $O$ fato de que todas as suas capacidades se coloquem em funcionamento determina também, naturalmente, que nenhuma delas possa realizar-se, nem de longe, em toda sua intensidade. O homem da cotidianidade é atuante e fruidor, ativo e receptivo, mas não tem nem tempo nem possibilidade de se absorver inteiramente em nenhum desses aspectos; por isso, não pode aguça-los em toda sua intensidade. (HELLER, 1985, p.18) 
Pelo exposto, parece que a vida cotidiana determina seus limites para o desenvolvimento de uma prática reflexiva, consciente, menos alienada no fetiche pelo objeto. Além disso, a pessoa já nasce inserida em sua cotidianidade; está repleta de emoções que interagem com circunstâncias heterogêneas, hierárquicas, mas de forma alguma eterna e imutável, modificando-se em razão das diferentes estruturas econômico-sociais. Prossigamos com Heller:

As necessidades humanas tornam-se conscientes, no indivíduo, sempre sob a forma de necessidades do Eu. O "Eu" tem fome, sente dores (físicas ou psíquicas); no "Eu" nascem os afetos e as paixões. A dinâmica básica da particularidade individual humana é a satisfação dessas necessidades do "Eu" [...].

Também enquanto indivíduo, portanto, é o homem um ser genérico, já que é produto e expressão de suas relações sociais, herdeiro e preservador do desenvolvimento humano; mas o representante do humano-genérico não é jamais um homem sozinho, mas sempre a integração (tribo, demos, estamento, classe, nação, humanidade) - bem como, freqüêntemente, várias integrações - cuja parte consciente é o homem e na qual se forma sua "consciência de nós". (HELLER, 1985, p.20-21).

Entendemos que a terminologia "humano-genérico", adotada por Heller, coloca a análise dos limites da conscientização através da prática do cotidiano, como possibilidade sempre presente de recuperação e superação do fetiche da mercadoria, nos momentos que encontram "consciência de nós". Essa interpretação se reforça quando Heller (1985) expõe:

É necessário o conhecimento do próprio Eu, o gnôthi seautón, o conhecimento e a apaixonada assimilação das intimações humano-genéricas, a fim de que o homem seja capaz de decidir elevando-se acima da cotidianidade.

A homogeneização em direção ao humano-genérico, a completa suspensão do particular-individual, a transformação em "homem inteiramente", é algo totalmente excepcional na maioria dos seres humanos. Nem sequer nas épocas ricas em grandes comoções sociais existem muitos pontos críticos desse tipo na vida do homem médio. A vida de muitos homens chega ao fim sem que 
se tenha produzido nem um só ponto crítico semelhante. A homeogenização em direção ao humano-genérico só deixa de ser excepcional, um caso singular, naqueles indivíduos cuja paixão dominante se orienta para o humano-genérico e, ademais, quando têm a capacidade de realizar tal paixão. Esse é o caso dos grandes e exemplares moralistas, dos estadistas (revolucionários), dos artistas e dos cientistas. De resto, a respeito do grande estadista, do revolucionário profissional, do grande artista, do grande cientista, deve-se afirmar que não apenas sua paixão principal, mas também seu trabalho principal, sua atividade básica, promovem a elevação ao humano-genérico e a implicam em si mesmos. Por isso, para tais pessoas, a homogeneização em "homem inteiramente" é elemento necessário de sua essência, da atividade básica de suas vidas.

Mas não se deve esquecer que o artista, o cientista, o estadista não vivem constantemente nessa tensão. Possuem também, como todos, os outros homens, uma vida cotidiana; o particularindividual manifesta-se neles, tal como nos demais homens. Tão-somente durante as fases produtivas essa particularidade é suspensa; e, quando isso ocorre, tais indivíduos se convertem, através da mediação de suas individualidades, em representantes do gênero humano, aparecendo como protagonistas do processo histórico global". (HELLER, 1985, p.28-29).

Procuremos compreender: cotidiano, classes sociais, movimentos sociais, relações de poder, raças e culturas, origens e comportamentos, empresas transnacionais e capital, líderes, gens, estado, história, emoções, tudo interagindo para sermos o que somos, interagindo na construção de um povo comunicativo, religioso e emotivo, concomitante com a tristeza, a miséria e o ceticismo. Opostọ que necessariamente interagem visto que a vida é social. Colocando a necessidade da compreensão dessa história para podermos superar essas contradições e dar um verdadeiro passo à frente. Como exemplo, poderíamos pensar na aposta do governo atual ao trabalhar com o discurso das emoções; na emoção da esperança vencer medos; medos como o cinismo, o ceticismo, o preconceito, o passado autoritário e o presente neoliberal, objetivando acreditarmos num novo futuro. No imediato parece um discurso tangido do populismo, tão caro à história da América Latina. Poder-se-ia questionar: voltaremos aos piores 
momentos do passado ou daremos um passo qualitativo à frente? Se, enquanto pessoas, somos um produto contraditório das relações sociais, a confiança colocada no novo governo parece dar novo fôlego para nosso cotidiano. Apesar das contradições, diferenças culturais e classistas, o novo discurso procuraria dar ênfase nas emoções, recolocando um autorespeito retirado há muito do brasileiro. Restaria saber, que medidas seriam colocadas em prática e até que ponto feririam suscetibilidades do latifúndio, da mídia e demais setores tradicionalmente solidificados da nossa história. Wolfgang Fritz Haug (1997, p.44) na sua crítica à estética da mercadoria apresenta uma reflexão interessante a respeito:

Os políticos precisam colocar-se como opção diante do público eleitor em intervalos mais ou menos regulares. Possivelmente é uma fraqueza - de qualquer modo, porém, é uma lei básica da "democracia" - "aquele que pretende ser eleito precisa se tornar o preferido, agradando a quem puder elegê-lo". Como agradar? Como tornar-se o preferido? Evidentemente, não é por meio de programas, nem de realizações objetivas. "Mesmo uma pessoa bem-sucedida não será eleita se não brilhar o suficiente na tela da TV". "Se uma pessoa, por exemplo, não é 'bem recebida' pelo telespectador, não é absolutamente por sua culpa, e para isso não importa a sua capacidade nem as qualidades de seu caráter". O que não conta, segundo a experiência adquirida por Helmut Schmidt - e reconhecida por ele também como norma de conduta -, é de quem e de que partido se trata, o que se quer e o que se faz. O que conta é a aparência, a impressão, a "recepção". Como impressionar os eleitores? Eles "são informados - ou enganados - sobre o seu provável candidato por ele mesmo". Como ele consegue enganálos? "Para isto ele conhece os desejos, os interesses e as curiosidades presentes em seus corações".

Diante do exposto, tentemos utilizar mais a razão e menos a emoção. Tratar-se-ia de um novo governo e não de um novo Estado. A proposta não seria transformar e sim reformar. Reforma tributária, reforma agrária, reforma da Previdência etc, em doses cuidadosamente homeopáticas. Porém, novo questionamento: haveria condições históricas para ser diferente? Mesmo que aceitemos o acaso na história, devemos admitir que ela possui dentro de suas contradições uma determinada lógica. A lógica do desgaste do governo anterior e das 
alianças do governo atual desbotando as bandeiras vermelhas, não colocaria a aposta popular numa "democracia universal", numa transição dentro da ordem institucional, numa conciliação de classes objetivando um passo "qualitativo" à frente? Resta a indagação de sabermos da possibilidade desse passo beneficiar indistintamente a todos. Historicamente parece possibilidade improvável. Ademais, "beneficiar indistintamente a todos" pressupõe não mexer nos alicerces do modo de produção capitalista imposto no Brasil. Se, como acreditara um velho filósofo alemão, a história se repete primeiro enquanto tragédia depois enquanto farsa, a esperança está em colocar essa história em nossas mãos e repeti-la tanto quanto possível na ética dos aspectos positivos. Ética que colocaria a necessidade sempre presente da superação das contradições pela prática consciente dentro do cotidiano, de um histórico de prática consciente, de práxis. Portanto, esperança que não colocaria o governo atual como farsa, mas como limite possível dentro do momento histórico vivido. Mas agora, governo já colocado, surge a questão: que fazer para realmente transformar? Ou o que poderia ter sido feito antes?

Por outro lado, um outro aspecto a ser abordado poderia estar no fetiche de colocarmos a emoção na esperança de uma pessoa, delegando nosso poder, nossa paixão, a líderes, partidos ou instituições. Parece não ser novidade o fato de que precisamos aprender com a história de que somos nós que a fazemos. Não a fazemos como queremos devido as circunstâncias impostas pelo passado e pelas forças contraditórias presentes, mas podemos transformá-la para melhor. Tudo indica que depende principalmente de nossa capacidade de organização. Nesse sentido, o aprendizado do cotidiano e o aprender e apreender das emoções tornar-se-ia fundamental para sermos uma pessoa dentro de um social construído de forma "qualitativa". Porém, não podermos antever qual será o encaminhamento para a construção dessa "evolução qualitativa". Essa construção parece depender das relações entre as classes, do Estado, dos movimentos sociais, etc., porque, se a iniciativa de superação das contradições depende de nossa iniciativa individual, por outro lado, essa existência individual está inserida dentro das organizações, a começar da própria família, das relações de trabalho, das empresas, igrejas, escolas etc. A questão que permanece estaria em como superar as contradições presentes no social e que se espelham 
no individual, no sentido de uma prática consciente em que não predominaria a organização sobre o indivíduo e tampouco o indivíduo sobre a organização. A questão principal, sempre presente, é que essa superação não é dada e sim construída, em permanente construção.

$\mathrm{O}$ valor das emoções parece depender das circunstâncias históricas na qual vivemos, no condicionamento da miséria, na adoração de fetiches, colocando as emoções à deriva dessa situação, conduzindo o espetáculo da busca da mercadoria e fazendo das emoções um sentimento de superficialidade e falsidade, tanto na posse quanto na relação. Como diria Guy Debord (1997, p.18):

A primeira fase da dominação da economia sobre a vida social acarretou, no modo de definir toda realização humana, uma evidente degradação do ser para o ter. A fase atual, em que a vida social está totalmente tomada pelos resultados acumulados da economia, leva a um deslizamento generalizado do ter para o parecer, do qual todo "ter" efetivo deve extrair seu prestígio imediato e sua função última. Ao mesmo tempo, toda realidade individual tornouse social, diretamente dependente da força social, moldada por ela. Só lhe é permitido aparecer naquilo que ela não é".

Portanto, depreende-se que vivemos numa sociedade onde os valores se invertem. Valorizam-se os que vivem do trabalho alheio, e o critério para a inteligência é dado em saber iludir. Colocam-se também os limites da pessoa enquanto indivíduo diante da força avassaladora das organizações classistas. A reflexão frente à dialética das emoções parece reconduzir-nos novamente ao momento inicial da mercadoria, ao espetáculo da sua realização. Prosseguindo com Debord (1997, p.24):

A alienação do espectador em favor do objeto contemplado (o que resulta de sua própria atividade inconsciente) se expressa assim: quanto mais ele contempla, menos vive; quanto mais aceita reconhecer-se nas imagens dominantes da necessidade, menos compreende sua própria existência e seu próprio desejo. Em relação ao homem que age, a exterioridade do espetáculo aparece no fato de seus próprios gestos já não serem seus, mas de um outro que os representa por ele. É por isso que o espectador não se sente em casa em lugar algum, pois o espetáculo está em toda parte". 
Tudo indica que a necessidade que temos de compreender as relações que nos conduzem coloca o espetáculo da mercadoria em todas as atividades, caracterizando hoje a força avassaladora da mídia, impondo sua imagem da realidade, educando consciências conforme suas necessidades econômicas, políticas e culturais, mas contradizendo à medida que a própria realidade (mediada por nós), que não se limita a ser delegada pela mídia, passa a negar esse discurso. Parece que à medida que ficamos condicionados a sermos consumidores reais, seja da mercadoria concreta (bens de produção) seja da abstrata (audiência televisiva), tornamo-nos também consumidores de ilusões. A mercadoria seria essa ilusão efetivamente real (realidade física imediata), e o espetáculo seria sua manifestação geral. Isto é, para aumentarmos a produção é preciso reinventar novas formas de organização do trabalho com menores custos, com apelos que atinjam os sentimentos dos subordinados e dos executivos. Para aumentarmos a circulação, a distribuição e o consumo, repete-se o processo. Retoma-se assim a dialética na qual os sentimentos passam a ser criados artificialmente, produzindo sempre mais velocidade, menos custos, numa competição infinita pelo "ter", colocando as próprias emoções enquanto mercadoria abstrata, sujeita ao fetiche da acumulação.

O valor das emoções parece estar distribuído na compreensão das necessidades criadas, sejam elas concretas ou abstratas, dentro do contexto social em que estamos inseridos. Da compreensão à transformação qualitativa das emoções, fica colocada a necessidade de mudança nas relações sociais. Mudança que parece exigir princípios éticos fundamentados na canalização de bons sentimentos, portanto, de boas relações sociais, perspectiva que não se vislumbra numa sociedade caracterizada pelo individualismo possessivo, pela fetichização da mercadoria. Nesse sentido esse processo de alienação cria, através de sujeitos coletivos, a necessidade de conscientização no apreender relações a que estamos submetidos. Une-se discurso e prática. Sujeito coletivo que recria a necessidade de desmistificação da dominação do objeto mercadoria sobre o indivíduo. Necessidade inerente nessa desmistificação, na construção do humano sobre a coisa. Recuperar-se o que foi invertido: os valores autênticos do humano sobre o objeto da mercadoria, colocando os sentimentos em sua direção mais evolutiva, filtrando-os para a socialização. 
A possibilidade da evolução das emoções acompanhar o avanço da tecnologia parece depender da recuperação do ser humano frente à coisificação. A introdução do sujeito coletivo, (semelhante ao intelectual orgânico de Gramsci), é no sentido de pensarmos uma nova proposta, sem doutrinação. Proposta que exigiria, para a construção do sujeito coletivo, formas de organizações democráticas com participação e peso igual de decisão em todos os níveis, respeitando-se diferenças individuais. Nesse sentido, coloca-se um gancho entre o saber, o compreender e o sentir. Gramsci (1978) tem uma passagem onde principia uma abordagem desse aspecto:

Passagem do saber ao compreender, ao sentir e, vice versa, do sentir ao compreender, ao saber.

O elemento popular "sente", mas nem sempre compreende ou sabe; o elemento intelectual "sabe" mas nem sempre compreende e especialmente "sente". Os dois extremos são, portanto, o pedantismo e o filisteísmo por um lado, e a paixão cega e o sectarismo por outro. Não quer dizer que o pedante não possa ser apaixonado, pelo contrário; o pedantismo apaixonado é tão ridículo e perigoso como o sectarismo e a demagogia mais desenfreada. O erro do intelectual consiste em crer que se possa saber sem compreender e especialmente sem sentir e ser apaixonado (não só do saber em si, mas pelo objeto do saber), isto é, em crer que o intelectual possa sê-lo ( e não um puro pedante) se distinto e afastado do povo-nação, isto é, sem sentir as paixões elementares do povo, compreendendo-as e, portanto, explicando-as e justificando-as na determinada situação histórica, e referenciando-as dialeticamente às leis da história, a uma superior concepção do mundo, científica e coerentemente elaborada, o "saber"; não se faz política-história sem esta paixão, isto é, sem esta conexão fundamental entre intelectuais e povonação. Na ausência de tal nexo, as relações do intelectual com o povo-nação são ou reduzem-se a relação de ordem puramente burocrática, formal; os intelectuais tornam-se uma casta ou um sacerdócio ( o chamado centralismo orgânico).

Se a relação entre intelectuais e povo-nação, entre dirigentes e dirigidos - entre governantes e governados - é dada por uma adesão orgânica em que o sentimento paixão se torna compreensão e, portanto, saber (não mecanicamente, mas de um modo vivo); só então a relação é de representação, e se verifica a troca de 
elementos individuais entre governados e governantes, entre dirigidos e dirigentes, isto é, se realiza a vida de conjunto que é unicamente a força social; cria-se o "bloco histórico" (p.101).

Tratar-se-ia, portanto, da construção da negação de relações de dominação e de poder à medida que se une o saber, o compreender e o sentir. Pensamos que não se trata de negar tal poder, mas distribuí-lo igualitariamente, respeitando-se as aptidões individuais de cada um. A motivação para a evolução de ordem qualitativa significaria diferenciar e apreender, e não competir e acumular. Do ponto de vista objetivo a iniciativa parece estar no sujeito coletivo, e do ponto de vista subjetivo na pessoa do cotidiano. Nesse sentido, a dificuldade estaria na interação desses dois momentos: sujeito coletivo e pessoa cotidiana. Enquanto possibilidade de superação, pensamos que a doutrina do pensamento único, da ideologia da irreversibilidade do capital, é uma falácia. Entendemos que o atual estado de coisas é um resultado de escolhas - ainda que nem sempre estejam sob controle de ninguém (assim como não controlamos os bens e meios de produção, tampouco a burguesia controla o mercado) e saiam diferentes do figurino em que foram cortadas - econômicas, políticas e culturais, portanto, determinadas por um modo de produção que é histórico, e não eterno. Nesse sentido, a possibilidade do conhecimento, da contradição e evolução de nossas emoções, sejam elas "negativas" ou "positivas", poderá ganhar nova dimensão à medida que superando-as, poderemos retomá-las, inclusive de forma lúdica, na perspectiva de uma nova sociedade. Isto posto, fechamos abrindo a reflexão com uma interessante contribuição de Paul-Laurente Assoun (1979, p.39):

[...] a influência caminha de baixo para cima no edifício. Todo acontecimento ideológico se encontra, por assim dizer, programado no substrato material: a ilusão ideológica consiste em crer que ela oculta em si mesma sua própria verdade. É nesse sentido que Marx declara que, "assim como não se julga um indivíduo pela idéia que ele tenha de si mesmo"[...] "não se julga [...] uma época de revolução de acordo com a consciência que ela faça de si mesma". É o dado que é a norma da idéia, ao passo que o sujeito social, produtor de idéias, é vítima dessa ilusão imanente de que é a idéia que ele tem de si que é o real. O real é mais 
fundamental que toda ideologia e a expõe: "Essa consciência", prossegue Marx, "se explicará pelas contrariedades da vida material, pelo conflito que opõe as forças produtivas sociais e as relações de produção". Não é por acaso que tal afirmação ocorra no quadro da exposição da teoria da revolução: a dialética ideológica alimenta-se da conflituosidade do real".

Pensamos que as contradições e suas conseqüentes superações não são arbitrárias. Necessitam de um sujeito-coletivo, de um humanismo-genérico - entre outras designações pelas quais o leitor optar - no sentido de atuar como mediação para a construção do ser humano, social, qualitativo. Parece evidente que os donos do poder possuem os meios necessários para estarem a frente desse processo buscando seus próprios interesses contra os da maioria. A administração dos sentimentos dos funcionários a serviço exclusivo do patronato empresarial, objetivando maior roubo do tempo de trabalho, dominação pelo discurso cooptativo da integração etc; indica não só o fator de estarem à frente do processo, mas também que estão constantemente preocupados em manter essa ordem. Por um lado o avanço da tecnologia os favorece para maiores ganhos em menos tempo, colocando também a concorrência de forma mais atroz. Por outro, aspectos tais, como a comunicação, entram na ordem da possibilidade de termos contradições mais próximas de nós. Sem dúvida uma faca de dois gumes, porém com poder de corte bem mais conhecido. 


\section{Referências}

ASSOUN, Paul-Laurent. Marx e a repetição histórica. Rio de Janeiro:

Civilização Brasileira, 1979.

DEBORD, Guy. A sociedade do espetáculo. Rio de Janeiro: Contraponto, 1997.

GRAMSCI, Antonio. Obras escolhidas. São Paulo: Martins Fontes, 1978.

HAUG, Wolfgang Fritz. Crítica da estética da mercadoria. São Paulo: Unesp, 1997.

HELLER, Agnes. O cotidiano e a história. 2.ed. Rio de Janeiro: Paz e Terra, 1985.

JAMESON, Fredric. A cultura do dinheiro: ensaios sobre a globalização. 2.ed. Petrópolis: Vozes, 2001.

\section{Abstract}

This paper aims to analyze emotions and their multiple determinations, in the sense of their integration, contradiction and superation in the light of dimensions of political, economical, cultural and social order.

Key words: merchandise fetish; human tendency towards materialism; daily life's spectacle; collective subject. 